Case Report

\section{Anomalies of coronary artery origin: About two cases}

\author{
Dioum $M^{1 *}$, Sarr EM', Manga $S^{2}$, Mingou $\mathrm{JS}^{3}$, Diack $\mathrm{A}^{3}$, Diop $\mathrm{AD}^{4}$, \\ Bindia $\mathrm{D}^{1}$, Diagne $\mathrm{PA}^{1}$, Sarr $\mathrm{AN}^{1}$ and Diop IB' \\ 'Department of Cardiology, National Teaching Hospital, FANN Dakar, Senegal \\ ${ }^{2}$ Department of Cardiology, Peace Hospital of Ziguinchor, Bangladesh \\ ${ }^{3}$ Department of Radiology, Principal Hospital of Dakar, Bangladesh \\ ${ }^{4}$ Department of Radiology, National Teaching Hospital. Fann Dakar, Bangladesh
}

\section{Introduction}

Anomalies of coronary artery origin are congenital malformations characterized by the abnormal birth of a coronary artery from the controlateral coronary aortic sinus (birth of the left coronary artery from the right sinus or birth of the right coronary artery from the left sinus). The artery concerned has an abnormal initial path between the aorta and the pulmonary artery; this segment is most often intramural, in the aortic wall. They are rare with a prevalence $(0.1 \%$ to $0.3 \%$ of the population).

They pose a high risk of sudden stress death related to exercise myocardial ischemia. The most common mode of discovery is aborted sudden death, but sometimes fortuitously. The contribution of multi-round CT is described for the positive diagnosis of these anatomical variations, sometimes delicate in coronary angiography, but also for the distinction between "benign" and "malignant" forms, potentially responsible for myocardial ischemia. Treatment is usually surgical in symptomatic forms. We report the cases of two patients with coronary connection abnormalities discovered in adulthood.

\section{Clinical Case 1}

This is M. I. N. aged 54 years with dyslipidemia as cardiovascular risk factor. He was sent by his cardiologist for a dyspnea stage II with disorders of the kinetics (anterior-septal and anterior hypokinesis) on the echocardiography. Other ultrasound parameters were normal. The electrocardiogram showed a regular sinus rhythm without disturbance of repolarization. The troponine was not dosed. Coronary angiography found a left atheromatous mesh; the right coronary artery (RCA) was not visualized. This examination was therefore supplemented by a CT scan that found a dominant nascent RCA at the anterolateral sinus with an inter-pulmonary pathway responsible for compression at its

\section{More Information}

*Address for Correspondence: Momar Dioum, Department of Cardiology, National Teaching Hospital, FANN Dakar, Senegal, Tel: 00221776551883;

Email:momar.dioum@yahoo.fr

\author{
Submitted: 29 August 2019 \\ Approved: 12 September 2019 \\ Published: 13 September 2019
}

How to cite this article: Dioum M, Sarr EM, Manga S, Mingou JS, Diack A, et al. Anomalies of coronary artery origin: About two cases. J Cardiol Cardiovasc Med. 2019; 4: 117-119.

DOI: dx.doi.org/10.29328/journal.jccm. 1001051

Copyright: @ 2019 Dioum M, et al. This is an open access article distributed under the Creative Commons Attribution License, which permits unrestricted use, distribution, and reproduction in any medium, provided the original work is properly cited

Keywords: Anomalies of coronary artery origin; Coronary CT scan

D) Check for updates

proximal segment (Figure 1). The patient did not received surgery because of the technical difficulty.

\section{Clinical Case 2}

Mr IB, aged 45, a teacher with multiple cardiovascular risk factors (hypertension, active smoking and overweight (BMI: $28 \mathrm{~kg} / \mathrm{m}^{2}$ ), is sent by cardiologist for suspected STEMI (ST segment elevation myocardial infarction). A typical chest pain

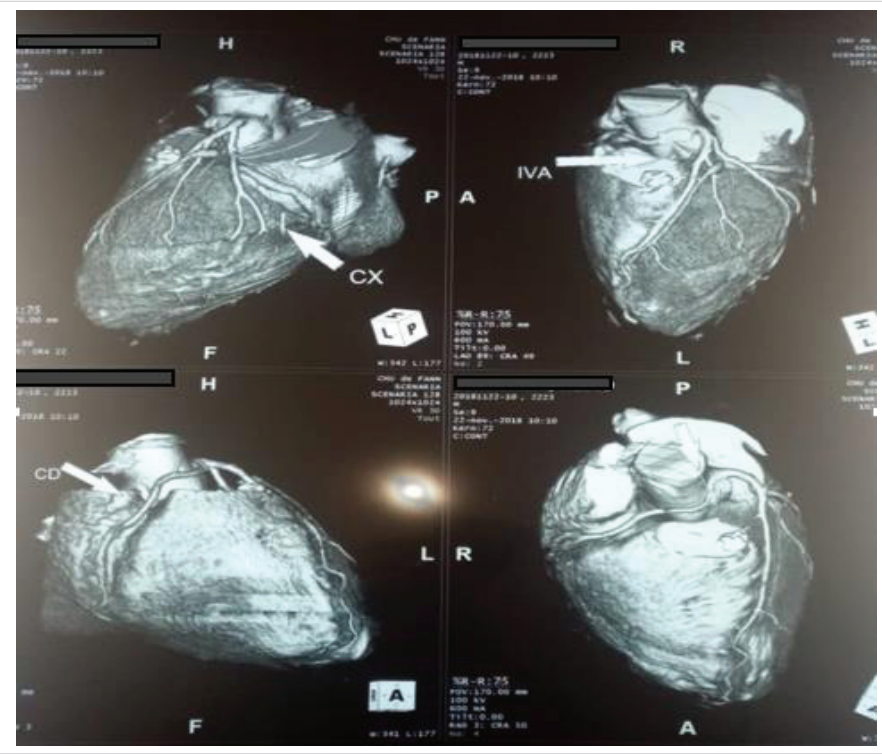

Figure 1: Right dominant coronary nascent at the left sinus with an inter aortopulmonary course. 


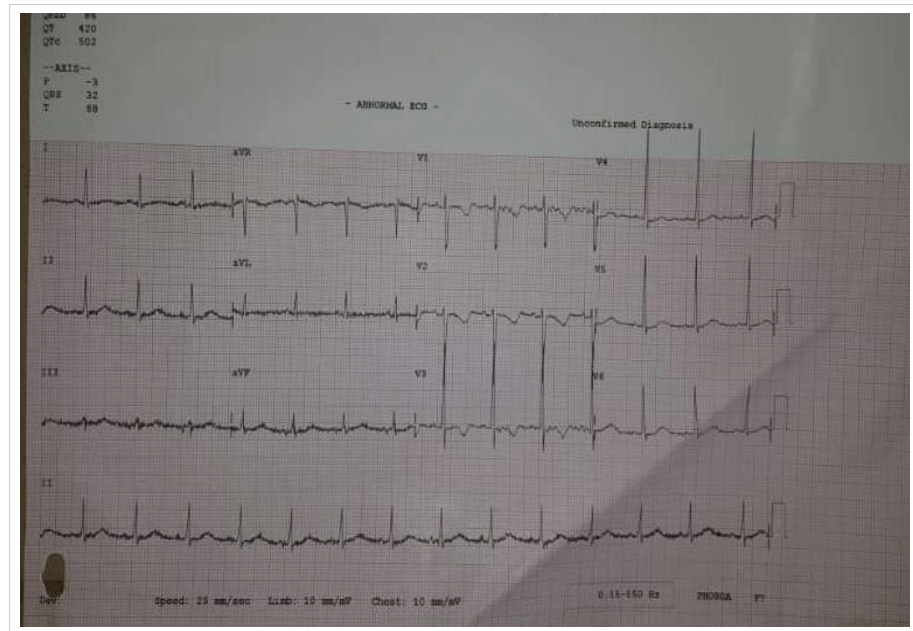

Figure 2: A typical anterolateral septal repolarization disturbances on ECG (Figure 1).

associated with a typical anterolateral septal repolarization disturbances on ECG (Figure 2). The troponine was not dosed.

A coronarography was performed, showing an angiographically normal left mesh; the RCA was not visualized. The CT scan found a birth and RCA path abnormality describing an aortopulmonary path (Figure 3). Stress ultrasound was negative. Clinical monitoring has been proposed.

\section{Discussion}

Among the various anomalies of birth and initial course of the coronary arteries, some are important to detect and correct because they expose to a risk of sudden death of effort. These are, in particular, malformations in which a coronary artery arises from the controlateral coronary sinus and presents an initial course between the aorta and the pulmonary artery. These abnormalities are rare and reach 0.1 to $0.3 \%$ of the entire population. Their interest lies in the fact that they are responsible for $15 \%$ to $20 \%$ of the sudden deaths observed among young athletes $[1,2]$.

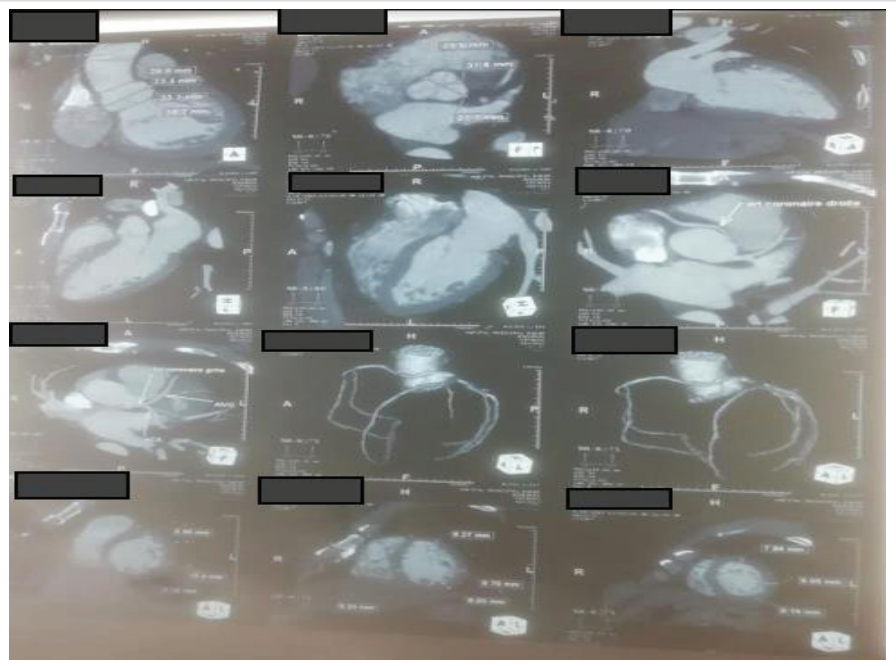

Figure 3: Anomaly of birth and path of the right coronary artery describing an aortopulmonary path.
The normal coronary artery is born in the center of "its" coronary sinus. The abnormal artery arises from the same sinus (an abnormal left main coronary artery LMCA arises from the right coronary sinus and vice versa). The ostium of the abnormal artery is often slit deformed and narrowed. The abnormal artery has an initial course between the aorta and the pulmonary artery, most often intramural, incorporated into the aortic wall. This intramural segment is generally in close relationship with the adjacent valvular commissure. The abnormal artery then resumes a normal epicardial path. The birth anomaly of the RCA is 5 to 6 times more common than that of the LMCA.

It is clearly established that these abnormalities (especially that of the LMCA, but also that of the RCA) may be responsible for sudden death, particularly during or after intense effort. Although the physiopathology remains poorly explained, the most likely mechanism is that of acute myocardial ischemia by compression of the abnormal artery, between the aorta and the pulmonary artery, while the large vessels dilate during the effort. This dynamic compression is probably aggravated by associated anatomical factor: deformation and stenosis of the coronary ostium, abnormality of the angle of emergence of the coronary artery, autonomic stenosis of the intramural path, especially with regard to the commissure of the valve $[3,4]$.

The most common mode of discovery remains "resucitated" sudden death occurring during or immediately after a very intense physical effort. Often, there are warning signs preceding the acute episode: chest pain, syncope or cardiac arrhythmia. More and more often, the abnormality is detected during a systematic echocardiographic assessment or performed for another cardiovascular reason. The angiographic diagnosis is generally easy, but it is sometimes difficult to specify the initial trajectory of the ectopic vessel joining its myocardial distribution zone.

Non-invasive imaging techniques (CT or MRI) are now essential to clarify the relationships of the ectopic vessel with adjacent structures, mainly the aorta and the pulmonary artery. The course of action is poorly codified for isolated abnormalities, which are known to be at risk for both indications and revascularization techniques, especially in case of accidental discovery.

There is a consensus to offer surgical treatment to patients with typical ischemic symptomatology of effort (anginal pain, angina, or even sudden death that could be resuscitated). When the anomaly is accidentally discovered during an echocardiographic examination in an asymptomatic patient or with a typical symptoms, every effort should be made to unmask stress ischemia (electrocardiogram, echocardiogram, exercise scintigraphic examination). If such ischemia is demonstrated, surgical treatment is indicated. Otherwise, strict regular supervision and contraindication of very violent efforts may be justified [5]. Surgical treatment consists of both 
aborting the path of the abnormal coronary artery between the aorta and the pulmonary artery and suppressing associated abnormalities (intramural pathway stenosis, coronary ostium stenosis).

The published series have few patients $[5,6]$. However, their results show that surgical treatment leads to the disappearance of signs of myocardial effort ischemia and very likely decreases the risk of sudden death.

\section{Conclusion}

Connective abnormalities of the coronary arteries are rare and mostly asymptomatic. Their highlighting is valuable because some are involved in the occurrence of sudden deaths. They must be operated when the certainty of myocardial ischemia of effort is acquired.

\section{References}

1. Penalver JM, Mosca RS, Weitz D, Phoon CK. Anomalous aortic origin of coronary arteries from the opposite sinus: a critical appraisal of risk.
BMC Cardiovasc Disord. 2012; 12: 83-92.

PubMed: https://www.ncbi.nlm.nih.gov/pubmed/23025810

2. Thiene G, Carturan E, Corrado D, Basso C. Prevention of sudden cardiac death in the young and in athletes: dream or reality? Cardiovasc Pathol. 2010; 19: 207-217.

PubMed: https://www.ncbi.nlm.nih.gov/pubmed/19535269

3. Basso C, Maron BJ, Corrado D, Thiene G. Clinical profile of congenital coronary artery anomalies with origin from the wrong aortic sinus leading to sudden death in young competitive athletes. J Am Coll Cardiol. 2000; 35: 1493-1501.

PubMed: https://www.ncbi.nlm.nih.gov/pubmed/10807452

4. Angelini P, Velasco JA, Flamm S. Coronary anomalies. Incidence, pathophysiology, and clinical relevance. Circulation. 2002; 105: 24492454.

PubMed: https://www.ncbi.nlm.nih.gov/pubmed/12021235

5. Mirchandani S, Phoon CK. Management of anomalous coronary arteries from the contralateral sinus. Int J Cardiol. 2005; 102: 383-389. PubMed: https://www.ncbi.nlm.nih.gov/pubmed/16004881

6. Van Son JA, Mohr FW. Modified unroofing procedure in anomalous aortic origin of left or right coronary artery. Ann Thorac Surg. 1997; 64: 568-569.

PubMed: https://www.ncbi.nlm.nih.gov/pubmed/9262625 